\title{
Metodologia para Elaboração de Objetivos Instrucionais para o Desenvolvimento de Cursos Hipermídia
}

\author{
André Luiz Brandão - Instituto Tecnológico da Aeronáutica \\ abrandao@ita.br \\ Daniela Leal Musa - Universidade Federal de São Paulo \\ musa@unifesp.br
Clovis Torres Fernandes - Instituto Tecnológico da Aeronáutica
clovistf@uol.com.br

\begin{abstract}
Resumo. O processo de elaboração de objetivos instrucionais é parte do desenvolvimento de cursos a distância ou presenciais. Constata-se que não existe uma metodologia padrão para a definição dos objetivos instrucionais de cursos hipermídia, embora existam diversos trabalhos sobre o assunto para outros tipos de cursos. Neste artigo apresenta-se uma proposta de metodologia para elaboração de objetivos instrucionais apropriados para o desenvolvimento de cursos hipermídia. O objetivo dessa proposta é dotar autores de cursos com ferramental auxiliar para a produção, de forma mais regular e metódica, de objetivos instrucionais mais bem definidos $e$ adequados ao domínio do curso alvo. Com tais objetivos instrucionais, podem-se elaborar atividades de aprendizagem que reflitam o que se pretende que os aprendizes saibam ao final de um dado curso hipermídia.
\end{abstract}

Palavras-chaves: Objetivos Instrucionais, Curso Hipermídia, Modelagem de Curso Hipermídia.

Abstract. The process of elaborating instructional objectives is part of the development of distance or classroom setting courses. There is no standard methodology in the literature that supports the definition of instructional objectives for hypermedia courses, although there are many studies on the subject with respect to other kind of courses. This paper presents a proposal of a methodology for developing instructional objectives for hypermedia courses. The proposal's aim is to provide course authors with an auxiliary tool for producing regularly and methodically well-defined learning objectives, more 
$2 \square$

suitable to the domain of the target course. Having these kinds of objectives, it is possible to elaborate learning activities that contemplates what a learner should know at the end of a hypermedia course.

\section{Keywords: Instructional Objectives, Hypermedia Courses, Hypermedia Course Modeling.}

\section{Introdução}

Neste trabalho entende-se por curso hipermídia qualquer material didático que é apresentado por meio da tecnologia hipermídia, quer seja na Web ou em outro meio qualquer. Ao se desenvolver um curso hipermídia, os autores devem estar conscientes da importância de um planejamento adequado para a estruturação do seu conteúdo didático na forma de atividades de aprendizagem. Para tanto, é necessário definir primeiro, como na confecção de qualquer tipo de curso ou atividade de treinamento convencional, os objetivos instrucionais; em seguida, pode-se elaborar o conteúdo hipermidiático que deve ser apresentado ou ficar disponível aos alunos, o tipo de navegação e os tipos de mídias adotadas. A modelagem de cursos hipermídia pode ser realizada em três fases, a saber [Kawasaki, 1996; Fernandes e Santibañez, 1999; Santibañez et al., 1999; Fernandes e Omar, 2001]: pré-autoria, autoria e leitura/apresentação.

$\mathrm{Na}$ fase de pré-autoria, o autor do curso elabora os objetivos instrucionais, planeja e modela o hiperdocumento ou conteúdo hipermídia do curso. Com base nos objetivos instrucionais, planejam-se roteiros educacionais ou atividades de aprendizagem para uso da tecnologia hipermídia, levando em conta aspectos didáticos e pedagógicos. Durante a fase de autoria, o autor cria efetivamente o hiperdocumento, seguindo os roteiros hipermidiáticos planejados. A execução do curso, ou seja, sua apresentação para o aprendiz é feita na fase de leitura/apresentação.

O presente trabalho está inserido na fase de pré-autoria da elaboração de cursos hipermídia. Alguns trabalhos tratam da elaboração de objetivos de treinamento [ICAO, 1990] e objetivos instrucionais [Mager, 1997], além de existir conceitos vinculados a esses, como são os casos de habilidades e competências. Muitas vezes dizse apenas que é necessário definir os objetivos instrucionais e que essa tarefa vai ficar a cargo de uma equipe multidisciplinar que conhece o domínio do curso alvo. Ainda que os trabalhos relacionados apresentem a importância dos objetivos, tanto de treinamento como instrucionais, constata-se que não existe na literatura uma metodologia que considere os diferentes aspectos envolvidos na elaboração de objetivos instrucionais apropriados para o desenvolvimento de cursos hipermídia. Sendo assim, apresenta-se neste trabalho uma proposta de metodologia para elaboração de objetivos instrucionais apropriados para o desenvolvimento de cursos hipermídia.

Este artigo está organizado da seguinte forma. Os conceitos base considerados são expostos na Seção 2. Na Seção 3, apresenta-se a metodologia proposta e, na Seção 
4, um exemplo simplificado de aplicação da metodologia. Finalmente, expõem-se as conclusões finais na Seção 5.

\section{Conceitos Base Considerados}

Os objetivos instrucionais são tratados de diferentes formas em alguns trabalhos. Os principais conceitos considerados na elaboração da metodologia proposta foram encontrados na metodologia TRAINAIR [ICAO, 1990], na proposta de definição de objetivos instrucionais de Mager [1997] e nos conceitos de competências e habilidades [Barros, 2008; Primo, 2005].

\subsection{Metodologia TRAINAIR}

O TRAINAIR - Training Development Guidelines é um documento que expõe a metodologia TRAINAIR, padronizada criada pela Organização de Aviação Civil Internacional (ICAO - International Civil Aviation Organization) [ICAO, 1990]. A utilização dessa metodologia induz a uma padronização no planejamento e preparação dos programas de treinamento, de forma que estes formem uma base comum de material que possa ser utilizada pelos diversos Centros de Instrução de Aviação Civil ao redor do mundo [ICAO, 1990; Oliveira e Fernandes, 1998]. Essa metodologia é composta pelas seguintes nove fases: (1) Estudo Preliminar, (2) Análise de Trabalho, (3) Análise de População, (4) Desenvolvimento de Currículo, (5) Desenvolvimento de Módulos, (6) Produção e Desenvolvimento de Testes, (7) Validação e Revisão, (8) Implementação e (9) Avaliação Pós-treino.

Das nove fases, apenas as fases Análise de Trabalho (2) e Desenvolvimento de Currículo (4) estão relacionadas com objetivos educacionais. Na Análise de Trabalho, devem-se listar quais serão as habilidades que os aprendizes deverão obter no decorrer do curso e, no Desenvolvimento de Currículo, é feita a elaboração da lista de objetivos de desempenho e seus respectivos objetivos intermediários, os quais determinarão a obtenção das habilidades que os aprendizes serão capazes de realizar.

$\mathrm{Na}$ Análise de Trabalho, que é a Fase 2, dividem-se os trabalhos em Deveres, Tarefas e Subtarefas. Para facilitar a coordenação dos Deveres, é aplicado o uso de Formulário de Lista de Tarefas [ICAO, 1991].

Outro formulário utilizado na Fase 2 é o Formulário de Análise em Profundidade de Tarefas. Esse formulário é utilizado para a descrição de cada tarefa, individualmente. Constam nele as seguintes informações: evento inicial e evento final, os quais definem os limites de cada tarefa; descrição de como a tarefa deve ser executada; requisitos de habilidades, conhecimentos e atitudes necessários para a execução da tarefa; e as condições de ambiente, equipamentos e documentação necessários.

O Formulário de Análise em Profundidade de Tarefas pode conter a lista das subtarefas em ordem seqüencial. Também deve constar no formulário o Padrão de Avaliação de Desempenho, que define os objetivos de desempenho do trabalho, o qual auxilia na identificação das necessidades de formação e nos objetivos do treinamento. 
A Fase 4 do processo de desenvolvimento da TRAINAIR tem, como proposta, iniciar o processo de elaboração de conteúdo das atividades de treinamento. Entre as atividades dessa fase, constam a definição dos objetivos dos trabalhos e seus conteúdos, além de descrever o que os aprendizes serão capazes de realizar após a aprendizagem de determinado conteúdo.

Para saber se os objetivos de desempenho foram atingidos pelos aprendizes, devem-se aplicar testes de verificação. Sendo assim, a descrição desses objetivos deve conter informações necessárias para o desenvolvimento dos testes, seqüenciamento e seleção do conteúdo e os métodos e as mídias utilizadas no curso.

Diferentes tipos de habilidades podem ser adquiridos na aprendizagem de conteúdos, segundo a metodologia TRAINAIR. As habilidades são divididas em habilidades intelectuais e físicas, sendo que a segunda se refere a ações de movimento dos aprendizes, como calibrar, ilustrar, entre outras possibilidades. As habilidades intelectuais são divididas da seguinte forma: classificação, aplicação de regras, diferenciação e resolução de problemas.

Para a definição de objetivos de treinamento também faz-se uso de formulários. O Formulário de Objetivos de Treinamento deve ser preenchido levando-se em conta qual o tipo de habilidade deve-se adquirir após a aplicação do treinamento. Esse formulário possibilita o acompanhamento de um objetivo final através de objetivos intermediários a serem atingidos. Os objetivos de treinamento são avaliados de acordo com o resultado final ou com observação ao processo no qual o aprendiz executou para a realização das tarefas.

\subsection{Definição de Objetivos Instrucionais Segundo Mager}

Objetivo instrucional é uma coleção de palavras, figuras e diagramas que deve expressar o que o autor do curso pretende que os aprendizes atinjam [Mager, 1997]. Apresenta as seguintes características:

- É relacionado com o resultado final, não com a avaliação do processo para atingir tal resultado.

- É específico e mensurável.

- É relacionado com os aprendizes, não com os instrutores.

Os objetivos instrucionais devem descrever quais são as capacidades dos aprendizes ao final de um curso ou treinamento. Deve informar as habilidades adquiridas, como o descrito pela seguinte frase: "o aprendiz estará apto a...".

A qualidade de objetivos usáveis está relacionada com a utilização de frases com verbos de menor ambigüidade e subjetividade possível. As frases devem descrever o que os aprendizes serão aptos a fazer, ou seja, descrever as ações e que os aprendizes terão condições de realizar após a realização da atividade de aprendizagem correspondente. A qualidade dos objetivos implica em ter três características desejáveis, que devem 
constituir resposta às seguintes perguntas: (a) O que o aprendiz será capaz de realizar? (b) Sob quais condições o aprendiz será capaz da realização? (c) Quão bem o aprendiz poderá realizar?

As características que devem constituir resposta às perguntas mencionadas são as seguintes:

- Desempenho - Deve-se listar as capacidades esperadas dos aprendizes.

- Condições - Deve-se expressar as condições da realização das capacidades.

- Critério - Deve-se descrever as capacidades aceitáveis pelo autor.

Por vezes, não é necessária condição específica ou critério indicado; no entanto, quanto mais informações objetivas forem especificadas, mais apropriados poderão ser definidos os objetivos instrucionais.

\subsection{Competências e Habilidades}

As competências e habilidades exigem domínio de conhecimentos. As competências se constituem num conjunto de conhecimentos, atitudes, capacidades e aptidões que habilitam alguém para vários desempenhos. Essas competências estão relacionadas com o seguinte [Educacional, 2008]: operações mentais, capacidades para usar as habilidades e emprego de atitudes adequadas à realização de tarefas e conhecimentos.

As competências e habilidades estão inseridas nos pilares da educação moderna os quais formam a base para a aprendizagem significativa [Barros, 2008]: aprender a aprender, aprender a fazer e aprender a ser. Considerando competências como conteúdo, conhecimento, teoria e habilidades em ação, elas estão caracterizadas pela função; por sua vez, as habilidades estão caracterizadas pela ação. Dessa forma, competência é o saber construído, elaborado e desenvolvido pelas muitas descobertas e redescobertas, enquanto as habilidades referem-se ao saber quando e como fazer [Barros, 2008].

De acordo com o Centro de Referência Educacional [Educacional, 2008], tem-se a seguinte caracterização: "As habilidades estão associadas ao saber fazer: ação física ou mental que indica a capacidade adquirida. Assim, identificar variáveis, compreender fenômenos, relacionar informações, analisar situações-problema, sintetizar, julgar, correlacionar e manipular são exemplos de habilidades. Já as competências são um conjunto de habilidades harmonicamente desenvolvidas e que caracterizam, por exemplo, uma função/profissão específica: ser arquiteto, médico ou professor de química. As habilidades devem ser desenvolvidas na busca das competências."

\section{Metodologia Proposta}

A metodologia proposta tem como objetivo auxiliar autores na elaboração de objetivos instrucionais de cursos hipermídia. Para isso, são levados em conta importantes aspectos do aprendizado, tais como saber (conhecimentos), saber fazer (habilidades) e 
$6 \square$

saber ser (atitudes) [Primo, 2005; Depresbiteres, 2001], também considerados na metodologia TRAINAIR [ICAO, 1990].

Para a elaboração dos objetivos instrucionais, propõem-se as seguintes três fases: Fase 1: Estudo do Domínio do Assunto Alvo, Fase 2: Análise de Habilidades e Fase 3: Análise de Atividades.

\subsection{Fase 1: Estudo do Domínio do Assunto Alvo}

O estudo do domínio do assunto alvo é indicado para que o autor adquira conhecimento necessário para elaboração do curso hipermídia desejado, mesmo que trabalhe com equipe de conhecedores do domínio. Nessa etapa, deve ser gerada uma estrutura de conceitos representativos do domínio. Pode ser composto por um mapa conceitual ou por uma lista de tópicos teóricos do domínio e sua respectiva hierarquia. De qualquer forma, em seguida deve-se indicar os conceitos ou tópicos devem ser abordados como pré-requisitos, de forma análoga ao que ocorre na Fase 1 (Estudo Preliminar) da metodologia TRAINAIR [ICAO, 1990].

$\mathrm{O}$ resultado desta fase corresponde a obter os conhecimentos (saber) essenciais do domínio do assunto alvo, que são os conceitos teóricos envolvidos na competência.

\subsection{Fase 2: Análise de Habilidades}

Nesta etapa o autor deve listar quais serão as habilidades que os aprendizes deverão obter ao realizar o curso. Na lista de habilidades gerada ao final desta etapa, podem ser utilizados tanto verbos que expressam ações, como aqueles que não expressam. Corresponde à Fase 2 (Análise de Trabalho) da metodologia TRAINAIR [ICAO, 1990].

As habilidades listadas são relacionadas diretamente com os conceitos ou tópicos teóricos levantados na Fase 1. Assim, essas habilidades ficam definidas hierarquicamente e o autor do curso poderá associar tais habilidades a futuras atividades, que serão levantadas na Fase 3.

$\mathrm{Na}$ lista de habilidades devem aparecer verbos que não precisam, necessariamente, expressar ações, mas devem demonstrar conhecimento do aprendiz, como identificar, saber, compreender, apreciar, entre outros. Sendo assim, a lista de habilidades corresponde à lista de habilidades intelectuais dos aprendizes. Contudo, as habilidades se ligam a atributos relacionados não apenas com o saber conhecer, mas também ao saber conviver e ao saber ser. $\mathrm{O}$ conceito de habilidade também varia de autor para autor.

Em geral, as habilidades são consideradas como algo menos amplo do que as competências. Assim, a competência estaria constituída por várias habilidades. Entretanto, uma habilidade não "pertence" a determinada competência, uma vez que uma mesma habilidade pode contribuir para competências diferentes [Educacional, 2008].

\subsection{Fase 3: Análise de Atividades}


Nesta fase é elaborada a lista de tarefas ou atividades de aprendizagem que poderão determinar a obtenção das habilidades que os aprendizes deverão demonstrar ao final do curso. Devem ser utilizados, exclusivamente, verbos que expressem ações dos aprendizes, caracterizando as habilidades físicas dos aprendizes - saber fazer. Corresponde à Fase 4 (Desenvolvimento de Currículo) da metodologia TRAINAIR [ICAO, 1990], levando-se em conta os objetivos instrucionais de Mager [1997].

Habilidades físicas devem ser descritas utilizando verbos que definem as ações que o aprendiz será capaz de realizar. Por exemplo, escrever, recitar, listar, sublinhar, circular etc. Além disso, a descrição deve estar de acordo com as características especificadas por Mager para objetivos instrucionais [Mager, 1997], a saber, desempenho, condições e critério, que serão apresentadas a seguir.

\subsubsection{Desempenho}

O desempenho deve ser descrito com frases que possibilitem a visualização, audição ou mensuração de alguma forma daquilo que o aprendiz faz ao demonstrar que é apto a realizar a tarefa sugerida pelo autor. Sendo assim, frases que não manifestem visibilidade, audição ou mensuração devem ser evitadas, como saber, compreender, apreciar, acreditar, ter fé em, entre outras. Ao invés, devem-se utilizar as seguintes, por exemplo: escrever, recitar, ordenar, construir etc.

Devem ser usados verbos que indiquem ações mensuráveis, de modo a indicar se aprendiz adquiriu o conhecimento ou habilidade pretendidos pelo autor. Se o autor deseja que o aprendiz obtenha certo conhecimento ou habilidade, o aprendiz deve ser capaz de realizar algo que demonstre se o aprendizado do dado conhecimento ou habilidade ocorreu de fato. Se o autor pretende que o aprendiz seja capaz de identificar algo, devem-se usar, entre outros, verbos como listar, sublinhar e circular. Por exemplo, seja o seguinte objetivo instrucional, "O aprendiz deve ser capaz de digitar uma carta". Nesse caso, "digitar uma carta" é desempenho.

\subsubsection{Condições}

As condições indicam de que maneira o aprendiz deve realizar a ação de desempenho indicada pelo autor. Essa característica indica o material, o que é permitido e o que não é permitido na realização de determinada tarefa. Por exemplo, seja o seguinte objetivo instrucional, "Dado um computador com processador de texto, o aprendiz deve ser capaz de digitar uma carta". Nesse caso, "Dado um computador com processador de texto" corresponde às condições oferecidas pelo autor ao aprendiz durante a tarefa de digitar uma carta. Sendo assim, ao descrever as condições, as seguintes perguntas devem ser respondidas:

- O que o aprendiz poderá utilizar na execução da tarefa quanto a ferramentas, materiais etc.?

- O que o aprendiz não pode utilizar na execução da tarefa? 
- Quais são as condições de ambiente para a realização da tarefa: é para ser feito em laboratório da escola ou em casa, em grupo ou individual?

\subsubsection{Critério}

O critério estabelece o nível de qualidade em que os aprendizes devem executar o desempenho. Ou seja, estabelece as características do produto final a ser apresentado pelo aprendiz em resposta a uma dada tarefa especificada pelo autor. A caracterização do critério expõe a condição de aceitação do desempenho realizado. Uma vez que os objetivos instrucionais devem ser mensuráveis, o critério define o que exatamente é medido.

As informações descritas para qualificar a execução de um desempenho não devem especificar características mínimas ou toleráveis, mas sim, características desejadas ou apropriadas. Dois aspectos principais podem ser levados em conta na descrição dos critérios:

- Intervalo de tempo - período de tempo desejável para a finalização do desempenho. Exemplo: "Ser capaz de correr uma distância de 100 metros em uma pista externa seca em um período de 14 segundos".

- Precisão - determina a exatidão pela qual o desempenho é realizado. Exemplo: "Ser capaz de falar as horas de um relógio de ponteiros com uma precisão mínima de 1 minuto, para mais ou para menos".

Ao definir objetivos instrucionais, Mager não faz uso de eventos. Contudo, propõe-se que se sejam estabelecidos os seguintes tipos de eventos:

- Inicial: evento em que se inicia uma atividade.

- Final: evento para a finalização de uma atividade.

O par de eventos Inicial e Final define os limites de cada tarefa ou atividade sugerida pelo autor do curso hipermídia.

\section{Exemplo de Aplicação da Metodologia}

Para ilustrar a aplicação da metodologia proposta, apresenta-se um exemplo no desenvolvimento de curso hipermídia sobre diagramas de classes da UML 2.0, uma linguagem visual usada para modelar programas orientados a objetos. Classes aqui são classes de objetos e diagramas de classes relacionam as diversas classes definidas num programa orientado a objetos. Na elaboração do curso, supões que o grupo alvo de aprendizes já tem conhecimento sobre os conceitos básicos de orientação a objetos. Dessa forma, o objetivo geral do curso é fazer com que o aprendiz possa ser capaz de ler, entender e criar diagramas de classes para um dado projeto de programa, de forma independente da metodologia de desenvolvimento de programas orientados a objetos a ser empregada. $\mathrm{O}$ curso pressupõe o uso do ambiente virtual de aprendizagem sendo desenvolvido no contexto do Projeto FAPESP TIDIA/Ae Aprendizado Eletrônico. 
A Tabela 1 apresenta parte do conteúdo selecionado para o curso de Diagramas de Classes, referente ao relacionamento de classes do tipo Associação. Seguindo os passos da Metodologia, após o estudo do domínio dos diagramas de classes da UML 2.0, foi selecionado o seguinte: Associação Unária, Binária e N-ária . Dentre os conteúdos da Associação Binária, estão os seguintes: Rótulo, Papel da Classe, Multiplicidade e Navegabilidade. Da Associação N-ária, consta o seguinte: Classes Associativas e Qualificador. Os conteúdos foram organizados em formato de Mapa Conceitual para melhor descrever a organização hierárquica dos conteúdos, como ilustra a Figura 1, referente aos conteúdos de Associação.

Tabela 1: Parte dos conteúdos selecionados.

\begin{tabular}{|c|c|c|}
\hline $\begin{array}{l}\text { Conceitos do } \\
\text { Domínio: }\end{array}$ & $\begin{array}{l}\text { O aprendiz deverá } \\
\text { ser capaz de: }\end{array}$ & Atividades: \\
\hline $\begin{array}{l}\text { Associação } \\
\text { - Unária } \\
\text { - Binária } \\
\text { Rótulo } \\
\text { Papel da Classe } \\
\text { Multiplicidade } \\
\text { Navegabilidade } \\
\text { - N-ária } \\
\text { Classes } \\
\text { Associativas } \\
\text { Qualificador }\end{array}$ & $\begin{array}{l}\text { - Conceituar os } \\
\text { tipos de } \\
\text { Associação de } \\
\text { classes } \\
\text { Identificar e } \\
\text { diferenciar os } \\
\text { tipos de } \\
\text { Associação de } \\
\text { classes } \\
\text { Aplicar os tipos } \\
\text { de Associação de } \\
\text { classes } \\
\text { Subobjetivos: } \\
\text { Conceituar e } \\
\text { rótulo da classe } \\
\text { em associações } \\
\text { binárias } \\
\text { Aplicar rótulo da } \\
\text { classe em } \\
\text { associações } \\
\text { binárias } \\
\text { Conceituar papel } \\
\text { da classe em } \\
\text { associações } \\
\text { binárias } \\
\text { Aplicar papel da } \\
\text { classe em } \\
\text { associações } \\
\text { binárias } \\
\text { Conceituar } \\
\text { multiplicidade } \\
\text { em relações } \\
\text { binárias } \\
\text { Aplicar } \\
\text { multiplicidade } \\
\text { em relações } \\
\text { binárias } \\
\text { Direcionar a }\end{array}$ & $\begin{array}{l}\text { - } \quad \text { Descrever o que é um relacionamento de associação de classes. } \\
\text { Desempenho: Descrever o que é um relacionamento de associação de classes. } \\
\text { Listar três tipos de associação (unária, binária e n-ária). } \\
\text { Desempenho: Listar três tipos de associação. } \\
\text { - } \\
\text { Descrever o conceito de cada um dos tipos de associação. } \\
\text { Desempenho: Descrever o conceito de cada um dos tipos de associação. } \\
\text { Exemplificar diferentes tipos de relacionamento de associação por } \\
\text { meio textual. } \\
\text { Desempenho: Exemplificar diferentes tipos de relacionamento de associação. } \\
\text { Condição: Por meio textual. } \\
\text { Exemplificar diferentes tipos de relacionamento de associação por } \\
\text { meio de desenho. } \\
\text { Desempenho: Exemplificar diferentes tipos de relacionamento de associação. } \\
\text { Condição: Por meio de desenho. } \\
\text { Dada uma situação problema, descrever as classes e seus diferentes } \\
\text { tipos de relacionamentos de associação. } \\
\text { Desempenho: Descrever as classes e seus diferentes tipos de relacionamentos } \\
\text { de associação. } \\
\text { - Condição: existência de uma situação problema. } \\
\text { Descrever o conceito de Rótulo, Papel da Classe e Multiplicidade. } \\
\text { Desempenho: Descrever o conceito de Rótulo, Papel da Classe e } \\
\text { Multiplicidade. } \\
\text { Descrever o que é navegabilidade. } \\
\text { Desempenho: Descrever o que é navegabilidade. } \\
\text { Elaborar um diagrama de classes que contenha rótulo, papel da } \\
\text { classe, multiplicidade e navegabilidade. } \\
\text { Desempenho: Elaborar um diagrama de classes. } \\
\text { - Condição: Contenha rótulo, papel da classe, multiplicidade e navegabilidade. } \\
\text { Descrever o conceito de Classes associativas e qualificador. } \\
\text { Desempenho: Descrever o conceito de Classes associativas e qualificador. } \\
\text { Dada uma situação problema, elaborar um diagrama de classes que } \\
\text { contenha classes associativas e qualificadores. } \\
\text { Desempenho: Elaborar um diagrama de classes que contenha classes } \\
\text { associativas e qualificadores. } \\
\text { Condição: Existência de uma situação problema. }\end{array}$ \\
\hline
\end{tabular}




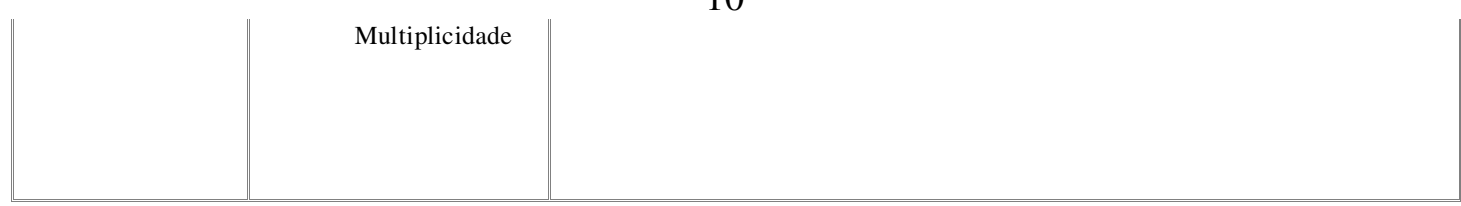

A Fase de Análise de Habilidades (Fase 2) foi seguida de acordo com o material selecionado do assunto alvo, observando quais as habilidades são as mais apropriadas. Para o exemplo descrito na Tabela 1, as habilidades foram referentes a conceituar, identificar e aplicar os conceitos envolvidos.

Assim que as habilidades foram listadas, partiu-se para a terceira fase de elaboração dos objetivos instrucionais: Análise de Atividades. Nessa fase, primeiramente foram elaboradas as frases descritivas das atividades que os aprendizes devem realizar para comprovar a satisfação das habilidades definidas. Após a elaboração das atividades, estas foram divididas em Desempenho, Condições e Critério, de acordo com Mager [1997].

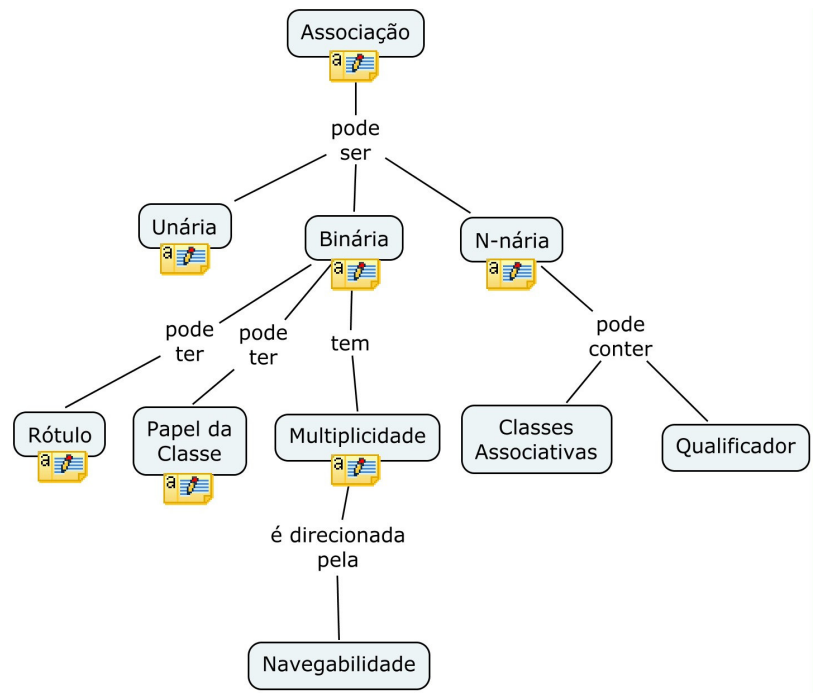

Figura 1: Mapa Conceitual para Relacionamento Associação.

O domínio completo do curso de Diagramas de Classes foi estudado e elaborado seguindo as fases de desenvolvimento de Cursos Hipermídia, a saber, Pré-autoria, Autoria e Leitura/Apresentação. Como mencionado anteriormente, destaca-se que, a metodologia de elaboração de objetivos instrucionais aqui apresentada está inserida na fase de Pré-autoria.

\section{Conclusões}

A metodologia proposta para elaboração de objetivos instrucionais para desenvolvimento de cursos hipermídia considerou alguns elementos da metodologia TRAINAIR, dos conceitos de Competências e Habilidades (saber conhecer, saber fazer e saber ser) e os objetivos instrucionais segundo Mager (Desempenho, Condição e 
$11 \square$

Critério). Tal metodologia está inserida na fase de Pré-autoria na elaboração de Cursos Hipermídia.

A metodologia proposta mostrou-se satisfatória no estudo de caso, tendo em vista que existiam dúvidas quanto à maneira de elaborar tais objetivos instrucionais. Essa metodologia, por utilizar conceitos de diferentes trabalhos, apresentou uma forma mais abrangente de expor o que o aprendiz deve ser capaz de realizar e as ações nas quais são realizadas para demonstrar conhecimento e habilidades no domínio alvo do curso.

A aplicação contínua da metodologia será realizada para reforçar a validade da mesma em diferentes cursos. Pretende-se que os autores de cursos, por causa da definição de objetivos instrucionais mais apropriados, tenham mais facilidade não planejamento e elaboração de roteiros educacionais hipermídia mais ricos didática e pedagogicamente. 
Por fim, destaca-se ainda o seguinte:

- Os objetivos instrucionais influenciam o trabalho do autor não só na fase de Préautoria, mas em todas as fases de desenvolvimento de cursos hipermídia.

- A metodologia proposta também pode ser aplicada no desenvolvimento de atividades de aprendizagem em cursos presenciais ou em outras metodologias de desenvolvimento de cursos hipermídia.

\section{AGRADECIMENTOS}

À FAPESP pelo apoio concedido no projeto TIDIA-Ae, proc. $\mathrm{n}^{\circ}$ 05/60621-02.

\section{REFERÊNCIAS BIBLIOGRÁFICAS}

Barros G. C. "Competências e Habilidades" Disponível em <http://br.geocities.com/gilianb_nte/ws_pessoal/corpo/sinteses/sint_05.htm> Acessado em 14 de maio de 2008.

Depresbiteres, L. "Avaliação: avaliando competências na escola de alguns ou na escola de todos?" Boletim Técnico do Senac, Rio de Janeiro, v. 27, n.3, pp. 37-47, set./ dez., 2001.

Educacional, Centro de Referência. "Competências e Habilidades" Disponível em $<$ http://www.centrorefeducacional.com.br/compehab.htm> Acessado em 11 de maio de 2008.

Fernandes, C. T. e Omar, N. "Education Via Internet: Comparative Assessment of Methodologies for Constructing Hypermedia Tools and Applications". In: Workshop Projeto PROTEM 2001. Disponível em vega.cnpq.br/pub/protem/workshop2001/educacao/artigos/imm-evi.rtf> Acessado em 12 de março de 2008.

Fernandes, C. T. ; Santibañez, M. R. F. "Characterization and modeling of hypermedia courses". In: ICECE'99 Rio de Janeiro. Proceedings, 1999.

ICAO - International Civil Aviation Organization. TRAINAIR - Training Development Guidelines. Montreal, 1990 (1).

Kawasaki, E. "Modelo e Metodologia para Projeto de Cursos Hipermídia”. Dissertação de Mestrado - Instituto Tecnológico de Aeronáutica, 1996.

Mager, R. F. "Preparing Instructional Objectives: A Critical Tool in the Development of Effective Instruction (Paperback)". Publisher Center for Effective Performance; 3rd edition, 1997.

Oliveira, J. M. P. e Fernandes, C. T. "Ambiente Hipertexto para Apoio ao Planejamento e Elaboração de Cursos de Treinamento Segundo a Metodologia TRAINAIR." Revista Brasileira de Informática na Educação, Páginas 67-82, Abril, 1998. 
$13 \square$

Primo, L. "Avaliação de competências em Cursos de EAD - Relato de Experiência" Boletim Técnico do Senac - Edição Especial sobre EAD, 2005. Disponível em < http://www.senac.br/BTS/313/boltec313f.html>, acessado em 10 de abril de 2008.

Santibañez, M. F., Zuasnábar, D. H. e Fernandes, C. (1999). "A Pre-authoring Environment for the Development of Hypermedia Courses". In B. Collis \& R. Oliver (Eds.), Proceedings of World Conference on Educational Multimedia, Hypermedia and Telecommunications (pp. 1111-1116). Chesapeake, VA: AACE, 1999. 